\title{
Publish or perish, but at what cost?
}

\begin{abstract}
The academic scientific enterprise rewards those with the longest CVs and the most publications. Under pressure to generate voluminous output, scientists often fall prey to double publishing, self plagiarism, and submitting the "minimal publishable unit." Are these ethical gray areas, or true transgressions?
\end{abstract}

I've taken to the editorial page in the past to discuss what is and is not allowed in the JCI vis-à-vis manipulation of images. Here, I want to discuss a grayer area of potential violations - those that concern ethics in writing. Specifically, is publishing the same set of data twice acceptable (clearly not), is using the same text in several articles plagiarism (perhaps), and is publishing newly obtained data after the fact acceptable (maybe)?

Let us start with the most blatant: a reader recently alerted us to a publication in a specialist journal that appeared to have reproduced, nearly verbatim, a recent JCI publication. The authors were the same, with the addition of two more authors on the other paper, and the data were identical. Based on the dates of submission, acceptance, and publication, it was clear that the $J C I$ article was published before the other was even submitted. How could this be? One of the first rules most scientists learn about publishing (whether or not they know the source) is the widely adopted Ingelfinger rule, named for a former editor of the New England Journal of Medicine who in 1969 declared that his journal would not consider a manuscript for publication if it was submitted simultaneously elsewhere or previously published in similar form. We all know that you can't just reproduce a work in its entirety in another journal, especially not without attribution or permission, and particularly when the original journal retains the copyright for the work, as the $J C I$ does.

I polled the JCI editors for their opinions on how to best penalize this infraction, other than to alert the other journal about withdrawing the paper, which it has now consented to do. The editors' reaction was mixed after the senior author explained the reason for the double publication: as a requirement for speaking at a particular symposium, the author had to publish the talk in the other journal. Some editors felt that this was outrageous and that we should report the authors to their institution and ban them from publishing for some period of time. Some felt that these sorts of requests (publishing a talk) are frequent, and that demanding a simple retraction from the other journal was enough.

A puzzling polarization, I thought. Some of the editors said that in similar cases, they would have published a summary, or refused to comply (would the organizers really have rescinded the invitation?), or perhaps sent in data generated after the paper was accepted that would be otherwise unpublishable on its own. This last point raised a few hackles in our discussion. Is it ethical to send in a paper that shows new data from a published study? Alternatively, if the published paper had a figure that showed a single experiment that was representative of four independent experiments, is it ethical for a new paper to show a different one of the four? Some editors felt this was common practice, while others decried it as a misrepresentation that bordered on fraudulent. authors have recycled text from previous publications into their new submissions without attribution to or authorization from the original source. This happens
We have also had a few cases wherein

more frequently with reviews than with original research articles, but is it any more acceptable in that format? While we understand that sometimes there is only one way to express an idea or concept and that using the same or very similar language is tolerable, repeating the same passages verbatim is not. In the case of a review, if there is nothing new to say, then don't agree to write the review - it wouldn't be very timely or much of an advance, and the referees will all note this in their comments.

Related to the case of double publication I noted earlier, it was rather easy to make the case to the editors of the other journal that they needed to retract their version of the article, given the clear violation of copyright law. Why do we retain copyright? Partly because it gives us the chance to monitor use of our content, how it is archived, and how it is used (and sometimes abused); partly because we gain some revenue from the licensing of our content. However, while we retain the copyright to all JCI content, we allow authors to reuse, republish, and distribute their articles for educational purposes and to include their articles in their institutional repositories. The authors' (noncommercial) use of their own article is not restricted in any way, except that they need to cite the JCI when they reuse it.

We do our best to ensure that readers of the $J C I$ can have confidence in the manuscripts we publish, but it is becoming impossible to establish a rule

uswerens for every sort of questionable practice we see.
Related to the case above, the editorial board decided to report the infraction to the proper authorities at the author's institution and allow them to determine whether further punitive action was necessary, but the outcome might have been different had there not been a plausible reason for the author's actions. Regardless, policing violations of ethics means keeping up with a moving target, and we welcome your feedback and responses to these issues.

\section{Ushma S. Neill Executive Editor}

